\title{
Female distance runners show a different response to post-workout consumption of wheat gluten hydrolysate compared to their male counterparts
}

\author{
TOMOMI HIRAO ${ }^{1}$, NATSUE KOIKAWA ${ }^{1}$, KAZUHIRO AOKI ${ }^{1}$, KEISHOKU SAKURABA ${ }^{1}$, \\ YUKI SHIMMURA $^{2}$, YOSHIO SUZUKI ${ }^{1}$ and KEISUKE SAWAKI ${ }^{1}$ \\ ${ }^{1}$ Department of Sports Science, School of Health and Sports Science, Juntendo University, \\ Chiba 270-1695; ${ }^{2}$ Nisshin Pharma Inc., Tokyo 101-8441, Japan
}

Received November 8, 2011; Accepted December 30, 2011

DOI: $10.3892 /$ etm.2012.446

\begin{abstract}
Wheat gluten hydrolysate (WGH) is rich in glutamyl residue; glutamine is considered a conditionally essential amino acid under physical stress. WGH has been reported to suppress post-exercise rises in serum creatine kinase in male distance runners. This study aimed to reproduce the effects in female distance runners under similar conditions. The study was conducted in a double-blinded crossover manner. Six female collegiate distance runners ingested WGH or a placebo after a 2-h run at an intensity estimated as $60-70 \%$ of their maximum oxygen uptake. Blood was sampled before, immediately after, and at 10 and $24 \mathrm{~h}$ after the run. Unlike those in male runners, serum creatine kinase (CK) increased slightly, with a peak at $10 \mathrm{~h}$ after the run, while plasma glutamine kept declining. The anti-inflammatory effect of WGH was not evident since the post-exercise elevation of $\mathrm{CK}$ was ambiguous. Plasma glutamine concentrations also showed a different kinetics from that in men.
\end{abstract}

\section{Introduction}

Glutamine, a conditionally essential amino acid, comprises approximately $60 \%$ of the free amino acids found in skeletal muscle and is closely associated with the synthesis and breakdown of muscle protein $(1,2)$. Chronic fatigue, underperformance and decreased plasma glutamine concentrations are features of athletes with overtraining syndrome (3). Therefore, glutamine is supplemented in exercise and sports training (1).

As wheat gluten is a protein rich in glutamine, its enzymatic hydrolysate is used for fortification of glutamine in clinical

Correspondence to: Dr Yoshio Suzuki, Department of Sports Science, School of Health and Sports Science, Juntendo University, 1-1 Hiraga-gakuendai, Inzai, Chiba 270-1695, Japan

E-mail: y_suzuki@sakura.juntendo.ac.jp

Key words: exercise, inflammation, glutamine, skeletal muscle, gender difference enteral nutrition, especially in immunonutrition. Recently, wheat gluten hydrolysate (WGH) was used for glutamine supplementation in athletes as well. When consumed after a half marathon, WGH suppressed increases in serum creatine kinase (CK) (4,5), suggesting the mitigation of muscle inflammation and promotion of recovery. Sawaki et al investigated changes in biochemical parameters among male runners with or without WGH intake after completing a half-marathon and a $45-\mathrm{km}$ run. Plasma Gln was elevated after the ingestion, representing that the glutamyl residue contained in WGH was absorbed and contributed to the plasma level. The increase in serum CK was suppressed at 90 min after WGH consumption, indicating that WGH inhibits post-exercise muscle inflammation (4). Koikawa et al validated these results through an additional investigation (5).

This anti-inflammatory effect of WGH has been investigated in male distance runners, while its effect in females has not been characterized. We, therefore, investigated the effects of WGH consumption on distance running in female runners.

\section{Materials and methods}

Subjects. Six female distance runners belonging to a university track team provided written, informed consent to participate in this study. Their age, height, weight, body fat ratio (\%) and personal best for 5,000-m races (mean $\pm \mathrm{SD}$ ) were, respectively, $19.8 \pm 1.6$ years, $157.3 \pm 5.2 \mathrm{~cm}, 48.2 \pm 5.8 \mathrm{~kg}, 13.6 \pm 0.8 \%$ and $16 \mathrm{~min} 34.61 \pm 19.31 \mathrm{sec}$. Their maximum oxygen uptake $\left(\mathrm{VO}_{2} \mathrm{max}\right)$ was estimated from their best time in a 12-min run (Table I).

Wheat gluten hydrolysate. One 4.5-g packet contained $3 \mathrm{~g}$ of WGH as a granulated powder supplement, citric acid, sugars and thickeners. The placebo supplement contained watersoluble dietary fiber replaced for WGH. Nisshin Pharma (Tokyo, Japan) prepared and provided the study supplements (Table II).

Study protocol. This randomized crossover, double-blind investigation comprised two 3-day sessions at an interval of 2 weeks between them. The runners were divided into two 
Table I. Baseline characteristics of the subjects.

\begin{tabular}{|c|c|c|c|c|c|c|}
\hline Subject $(n=6)$ & Age (years) & Height (cm) & Weight (kg) & Body fat $(\%)$ & Personal best at $5,000 \mathrm{~m}$ & $\mathrm{VO}_{2} \max (\mathrm{ml} / \mathrm{kg} / \mathrm{min})$ \\
\hline A & 21.0 & 162.5 & 52.5 & 14.4 & $16 \mathrm{~min} 08.76 \mathrm{sec}$ & 62.5 \\
\hline B & 18.0 & 155.0 & 40.6 & 12.8 & $16 \mathrm{~min} 55.57 \mathrm{sec}$ & 66.8 \\
\hline $\mathrm{C}$ & 20.0 & 149.0 & 43.0 & 14.2 & $16 \mathrm{~min} 19.72 \mathrm{sec}$ & 59.4 \\
\hline $\mathrm{D}$ & 22.0 & 155.0 & 46.0 & 12.8 & $16 \mathrm{~min} 38.00 \mathrm{sec}$ & 61.1 \\
\hline $\mathrm{E}$ & 20.0 & 162.1 & 54.3 & 13.0 & $16 \mathrm{~min} 56.77 \mathrm{sec}$ & 65.8 \\
\hline $\mathrm{F}$ & 18.0 & 160.0 & 53.0 & 14.4 & $16 \mathrm{~min} 28.87 \mathrm{sec}$ & 65.8 \\
\hline Mean & 19.8 & 157.3 & 48.2 & 13.6 & $16 \mathrm{~min} 34.61 \mathrm{sec}$ & 63.6 \\
\hline SD & 1.6 & 5.2 & 5.8 & 0.8 & $19.31 \mathrm{sec}$ & 3.0 \\
\hline
\end{tabular}

Table II. Composition of the wheat gluten hydrolysate (WGH) study supplement and placebo (per six-packet dose).

\begin{tabular}{llr}
\hline $\begin{array}{l}\text { Study } \\
\text { supplement }\end{array}$ & \multicolumn{1}{c}{ Composition } & Content $(\mathrm{g})$ \\
\hline WGH & Wheat gluten hydrolysate & 18.0 \\
& Anhydrous glucose & 6.0 \\
& Anhydrous citric acid & 2.7 \\
& Sucralose (as sweetener) & 0.048 \\
& Lemon flavor & 0.252 \\
& Pullulan (as thickener) & 0.405 \\
Placebo & Polydextrose & 18.0 \\
& Anhydrous glucose & 6.0 \\
& Anhydrous citric acid & 2.7 \\
& Sucralose (as sweetener) & 0.048 \\
& Lemon flavor & 0.252 \\
& Pullulan (as thickener) & 0.405 \\
\hline
\end{tabular}

groups, three each, and performed a 2-h run at a pace of $190-200 \mathrm{~m} / \mathrm{min}$. One group was given WGH, while the other group received the placebo at the first session, and then the supplement was switched at the second session.

The runners refrained from training on the day before the run. On the day of the experiment, a blood sample was drawn from the median cubital vein before and immediately after the 2-h run. The runners then ingested six packets of WGH or placebo supplements, and blood was collected at 10 and $24 \mathrm{~h}$ later.

White blood cell count (WBC) and serum CK activities were determined in the blood samples, and plasma glutamine concentrations were measured in the samples collected from before, immediately and $10 \mathrm{~h}$ after the run. SRL (Tokyo, Japan) conducted the analyses according to the methods standardized by the Japan Society of Clinical Chemistry.

Nutritional intake of the runners was determined based on the 'Run! x Shoku-net Athlete Dietary Advice' program (Quality Life Service, Kanagawa, Japan). The program requires detailed documentation of the type and amount of food that has been consumed on a survey form and photographs of described meals before and after consumption. Energy and nutrient intake were calculated from the data on the survey forms and from the photographs. The survey proceeded during the study from breakfast on the pre-run day to breakfast on the day after the run.

All the runners participated in the same run and were not permitted to participate in any strength conditioning or other intense training. Fig. 1 shows the schedule and measurements taken during the study.

The protocol of this study was reviewed and approved by the Ethics Committee of Juntendo University.

Statistical analysis. All data are expressed as the means \pm SD. Serum CK is expressed relative to the post-workout level, which was defined as 100. Differences between the groups were assessed using a paired t-test. The criterion for statistical significance was set at $\mathrm{p}<0.05$.

\section{Results}

The subjects ran $\sim 23 \mathrm{~km}$ at a mean speed of $191.7 \mathrm{~m} / \mathrm{min}$ during the 2 -h run. The workout intensity, estimated by their maximal oxygen uptake of $63.6 \pm 3.0 \mathrm{ml} / \mathrm{kg} / \mathrm{min}$, was $63.8 \%$ of $\mathrm{VO}_{2} \max$.

Serum CK increased, peaked at $10 \mathrm{~h}$ after the run, and then declined (Table III). When post-run activity was normalized at a value of 100 due to large individual differences, the decline from 10 to $24 \mathrm{~h}$ after the run was significant $(\mathrm{p}<0.05)$ in the WGH, but not in the placebo group. However serum CK levels did not significantly differ between the two groups at either 10 or $24 \mathrm{~h}$ after the run.

The WBC counts in the WGH group increased from $5.3 \pm 1.2 \times 10^{3} / \mu 1$ before, to a peak of $5.8 \pm 1.9 \times 10^{3} / \mu 1$ immediately after the run, and then gradually decreased to the level before the run. On the other hand WBC counts in the placebo group were elevated by the 2 - $\mathrm{h}$ run to a peak at $10 \mathrm{~h}$ thereafter, and then declined. The decline significantly differed between 10 and $24 \mathrm{~h}$ after the race $(\mathrm{p}<0.05$; Table III).

Mean plasma glutamine concentrations consistently declined from before to $10 \mathrm{~h}$ after the run in both groups with no significant differences between them (Table III).

No difference was observed in macronutrient intake between the placebo and WGH groups (Table IV). 


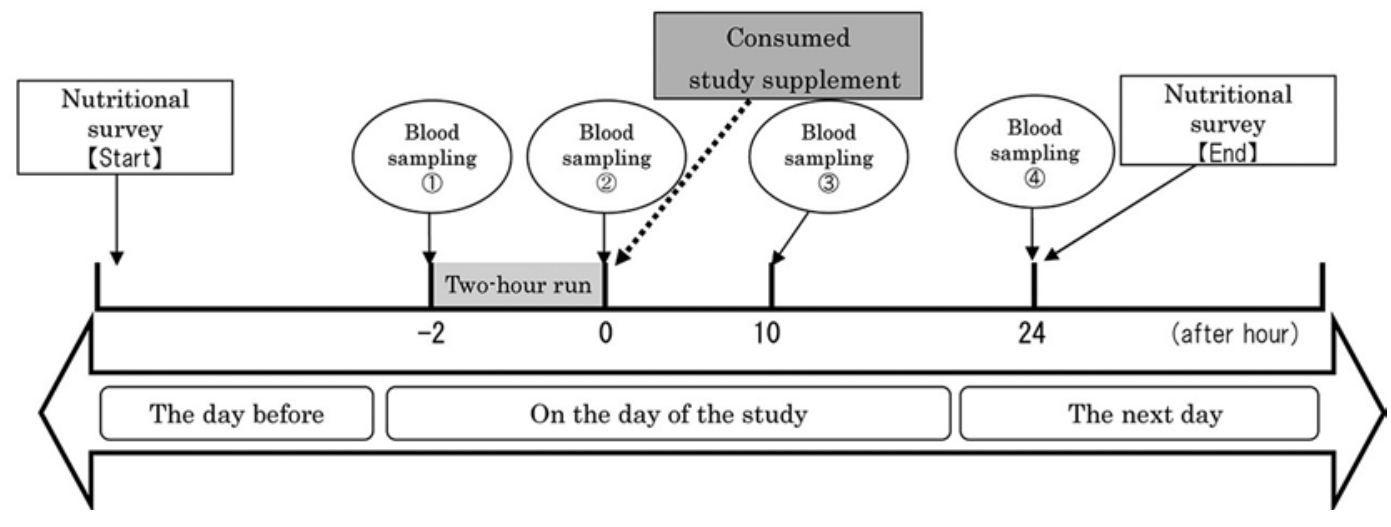

Figure 1. Study protocol.

Table III. Transition of the biomarkers before and after a 2-h run (mean \pm SD).

\begin{tabular}{|c|c|c|c|c|c|}
\hline Parameter (unit) <normal range $>$ & Group & Before & Immediately after run & $10 \mathrm{~h}$ after run & $24 \mathrm{~h}$ after run \\
\hline \multicolumn{6}{|l|}{$\mathrm{CK}(\mathrm{U} / \mathrm{l})<45-210>$} \\
\hline & WGH & $234 \pm 99.3$ & $319 \pm 119.8$ & $338 \pm 113.8$ & $312 \pm 118.5$ \\
\hline & Placebo & $199 \pm 55.3$ & $295 \pm 76.3$ & $330 \pm 139.1$ & $306 \pm 120.7$ \\
\hline \multicolumn{6}{|l|}{ WBC $\left(10^{3} / \mu 1\right)<3.5-9.1>$} \\
\hline & WGH & $5.3 \pm 1.2$ & $5.8 \pm 1.9$ & $5.5 \pm 1.2$ & $5.3 \pm 1.7$ \\
\hline & Placebo & $5.7 \pm 1.9$ & $5.9 \pm 1.5$ & $6.7 \pm 2.2$ & $5.5 \pm 2.1$ \\
\hline \multicolumn{6}{|l|}{$\mathrm{Gln}(\mathrm{nmol} / \mathrm{ml})<478.3-658.5>$} \\
\hline & WGH & $691 \pm 40.9$ & $656 \pm 53.2$ & $633 \pm 26.8$ & - \\
\hline & Placebo & $702 \pm 73.3$ & $648 \pm 83.9$ & $629 \pm 74.4$ & - \\
\hline
\end{tabular}

CK, creatine kinase; WBC, white blood cell count; Gln, glutamine.

Table IV. Macronutrient intake during the study (mean \pm SD).

\begin{tabular}{lcccc}
\hline Group & Energy (kcal/day) & Protein (g/day) & Lipids (g/day) & Carbohydrates (g/day) \\
\hline WGH group & $1,976 \pm 467.4$ & $75.1 \pm 12.1$ & $63.5 \pm 14.7$ & $272.6 \pm 74.1$ \\
Placebo group & $1,678 \pm 336.8$ & $65.8 \pm 16.7$ & $53.5 \pm 9.0$ & $239.4 \pm 51.8$ \\
\hline
\end{tabular}

\section{Discussion}

Sustained running, defined as running for 1-3 $\mathrm{h}$ at a pace of $40-75 \%$ of $\mathrm{VO}_{2}$ max, is regarded as the fundamental training for long distance runners to build aerobic capacity. Glycogen in the skeletal muscles is exhausted within $2 \mathrm{~h}$ of exercising at $60-70 \%$ of $\mathrm{VO}_{2} \max (6)$. Therefore, the exercise load was set as a 2-h sustained running at a pace of 190-200 $\mathrm{m} / \mathrm{min}$, and intensity was estimated as $60-70 \%$ of $\mathrm{VO}_{2}$ max.

Extensive exercise results in delayed-onset muscle soreness (DOMS), with an increase in serum CK activity and a decrease in muscular strength (7). Serum CK is thus considered an indicator of muscular damage generated by training. Post-run levels of serum CK peak at $24 \mathrm{~h}$ after completing a full marathon at $410 \pm 164 \mathrm{U} / 1$ (8) and a $100-\mathrm{km}$ run at 7,012 $\pm 2,262 \mathrm{U} / 1$ (9). By contrast, mean serum CK in the present study peaked at $10 \mathrm{~h}$ after the run and then declined. These findings indicate that the run in this study was less intensive than a full marathon or a $100-\mathrm{km}$ run. Indeed, the pace was moderate and the duration was shorter. Swaminathan et al (10) identified a significant correlation between lean body mass and serum CK activity. Therefore, the absence of the expected increase in serum CK may be attributed to the gender of the subjects, since female runners have less lean body mass than male runners.

The serum CK activities significantly decreased from 10 to $24 \mathrm{~h}$ after the run in the WGH $(\mathrm{p}<0.05)$, but not in the placebo group, when adjusted by the value obtained immediately thereafter that was designated as 100 . However, the difference between the two groups was not significant. The rise in serum CK activity up to $24 \mathrm{~h}$ after the run was approximately $10 \%$ of that immediately after the run. The response of CK could 
be too small to detect the anti-inflammatory effect of WGH in these female runners.

The increase in the WBC count after an endurance exercise is mainly due to the neutrophils mobilized into circulation (11). The WBC counts in the WGH group peaked immediately after the 2 -h run and subsequently declined to the pre-run level, whereas those in the placebo group remained elevated for up to $10 \mathrm{~h}$ after the run. This may reflect prolonged excitation in the placebo group, but the changes were within the normal range.

Glutamine is the most abundant amino acid in the body, and skeletal muscle is the primary source of plasma glutamine. Plasma concentrations of glutamine fall after intensive exercise, and also in athletes with overtraining syndrome. Since the glutamine supply cannot meet its demand under physical stress condition, it is considered to be a conditionally essential amino acid (12).

Plasma glutamine concentrations markedly decline at $1 \mathrm{~h}$ after completing a 3 -h workout at $55 \%$ of $\mathrm{VO}_{2} \max (13)$. Four hours of sustained exercise at $50 \%$ of $\mathrm{VO}_{2}$ max cause a $60 \%$ decrease in glutamine concentrations from baseline that recovers to $88 \%$ of baseline after $5.5 \mathrm{~h}$ (14). According to these data, we hypothesized that plasma glutamine concentration should decrease after a 2-h run and then recover within $10 \mathrm{~h}$. Therefore plasma glutamine was monitored up to $10 \mathrm{~h}$ after a 2-h run. However, it was even lower at $10 \mathrm{~h}$ than immediately after the run. Since plasma glutamine is supplied by skeletal muscle, the lower lean body mass in female runners may have contributed to these findings.

This study aimed to confirm the anti-inflammatory effect of WGH intake on changes in biomarkers associated with running in female distance runners. However, we could not achieve this goal because the kinetics of the biomarker were different from that hypothesized based on the male runners; changes in serum CK were insufficient and plasma glutamine remained decreased for up to $10 \mathrm{~h}$ after a 2 -h run. The insignificant changes in serum CK may have been due to the moderate intensity of the workout, although changes in plasma glutamine levels seemed to contradict this notion as they continued to decrease for up to $10 \mathrm{~h}$ after the run. As skeletal muscle is the source of both CK and glutamine, the smaller skeletal muscle mass in female runners may have affected the results.

Since human trials with extensive exercise load tend to be conducted with male subjects, studies investigating female cases are limited. Thus, responses induced by intense physical stress in females must often be estimated extrapolating from male cases assuming the same kinetics. However, as described in this study, there could be gender differences in the kinetics of post-exercise biomarkers. It should be worthwhile to examine the response to exercise in female subjects contrasting their male counterparts.

\section{Acknowledgements}

This study was partly granted by Nisshin Pharma Inc. (Tokyo, Japan), which was the manufacturer of the wheat gluten hydrolysate used in this study.

\section{References}

1. Gleeson M: Dosing and efficacy of glutamine supplementation in human exercise and sport training. J Nutr 138: S2045-S2049, 2008.

2. Souba WW, Smith RJ and Willmore DW: Glutamine metabolism by the intestinal tract. J Parenter Enteral Nutr 9: 608-617, 1985.

3. Rowbottom DG, Keast D, Goodman C and Morton AR: The hematological, biochemical and immunological profile of athletes suffering from the overtraining syndrome. Eur J Appl Physiol 70: 502-509, 1995.

4. Sawaki K, Takaoka I, Sakuraba K and Suzuki Y: Effect of distance running and subsequent intake of glutamine rich peptide on biomedical parameters of male Japanese athletes. Nutr Res 24: 59-71, 2004.

5. Koikawa N, Nakamura A, Nagaoka I, Aoki K, Sawaki K and Suzuki Y: Delayed-onset muscle injury and its modification by wheat gluten hydrolysate. Nutrition 25: 493-498, 2009.

6. Saltin B and Gollnick PD: Fuel for muscular exercise: role of carbohydrate. In: Exercise Nutrition and Energy Metabolism. Horton ES and Terjung RL (eds.). Macmillan, New York, pp45-71, 1988.

7. Armstrong RB: Mechanisms of exercise-induced delayed onset muscular soreness: a brief review. Med Sci Sports Exerc 16: 529-538, 1984.

8. Suzuki K, Nakaji S, Yamada M, Liu Q, Kurakake S, Okamura N, Kumae T, Umeda T and Sugawara K: Impact of a competitive marathon race on systemic cytokine and neutrophil responses. Med Sci Sports Exerc 35: 348-355, 2003.

9. Gomez-Merino D, Drogou C, Guezennec CY, Burnat P, Bourrilhon C, Tomaszewski A, Milhau S and Chennaoui M: Comparison of systemic cytokine responses after a long distance triathlon and a 100-km run: relationship to metabolic and inflammatory processes. Eur Cytokine Netw 17: 117-124, 2006.

10. Swaminathan R, Ho CS and Donnan SPB: Body composition and plasma creatine kinase activity. Ann Clin Biochem 25: 389-391, 1988.

11. Suzuki K, Totsuka M, Nakaji S, Yamada M, Kudoh S, Liu Q, Sugawara K, Yamaya K and Sato K: Endurance exercise causes interaction among stress hormones, cytokines, neutrophil dynamics, and muscle damage. J Appl Physiol 87: 1360-1367, 1999.

12. Calder PC and Yaqoob P: Glutamine and the immune system. Amino Acids 17: 227-241, 1999.

13. Robson PJ, Blannin AK, Walsh NP, Castell LM and Gleeson M: Effects of exercise intensity, duration and recovery on in vitro neutrophil function in male athletes. Int J Sports Med 20: 128-135, 1999.

14. Rennie MJ, Edwards RH, Krywawych S, Davies CT, Halliday D, Waterlow JC and Millward DJ: Effect of exercise on protein turnover in man. Clin Sci (Lond) 61: 627-639, 1981. 